\title{
Erratum to: New Activities for Cultural Heritage
}

\author{
Marco Ceccarelli ${ }^{1(\bowtie)}$, Michela Cigola ${ }^{2}$, and Giuseppe Recinto ${ }^{3}$ \\ ${ }^{1}$ LARM: Laboratory of Robotics and Mechatronics, Department of Civil \\ and Mechanical Engineering, University of Cassino and South Latium, Cassino, Italy \\ ceccarelli@unicas.it \\ 2 DART: Laboratory for Documentation, Analysis, Survey and Techniques \\ on Architecture and Territory, Department of Civil and Mechanical Engineering, \\ University of Cassino and South Latium, Cassino, Italy \\ 3 Department of Economics and Laws, University of Cassino and South Latium, \\ Cassino, Italy
}

\section{Erratum to: \\ M. Ceccarelli et al. (eds.), New Activities for Cultural Heritage, https://doi.org/10.1007/978-3-319-67026-3}

In the original version of the book, misspelt author name "Mabrogi" has to be corrected to read as "Ambrogi" in FM, BM and Chapter 2. The erratum book has been updated with the change.

The updated online version of this book can be found at https://doi.org/10.1007/978-3-319-67026-3_2

https://doi.org/10.1007/978-3-319-67026-3 